\title{
FAMÍLIA E O PROCESSO DE DIFERENCIAÇÃO NA PERSPECTIVA DE MURRAY BOWEN: UM ESTUDO DE CASO'
}

\section{Elizabeth Medeiros de Almeida Martins Elaine Pedreira Rabinovich Célia Nunes Silva}

Resumo: Este estudo teve como objetivo investigar a aplicabilidade do conceito de diferenciação do self elaborado por Murray Bowen na terapia da família. Focalizou a história de uma família mostrando como as histórias de vida do casal, a partir das primeiras triangulações, tanto na família nuclear quanto na extensa, foram transmitidas entre gerações até gerar uma história renovada do casal e de sua própria família.

Palavras-chave: Família. Diferenciação do self. Sistema emocional de relações. Multigeracional.

Este estudo tem como objetivo geral investigar a aplicabilidade do conceito de diferenciação do self elaborado por Murray Bowen em casos de atendimento clínico na Terapia de Família. Trata-se de um estudo de caso a partir de atendimentos terapêuticos em que se buscou clarificar as relações e identificar os processos subjacentes. Aqui será apresentado o estudo de uma das famílias enfocadas.

A família atendida procurou o Centro de Orientação Familiar ${ }^{2}$ pela dificuldade de assumir o custo de uma psicoterapia, da qual participou pela primeira vez. A

1 Dissertação apresentada à Universidade Católica do Salvador, em 2005, como requisito parcial para obtenção do título de Mestre em Família na Sociedade Contemporânea. Orientação de Elaine Pedreira Rabinovich. Co-orientação de Célia Nunes Silva.

2 COFAM - Pertencente ao Movimento Familiar Cristão (MFC) de Salvador-BA, onde funciona o Curso de Especialização e Formação em Terapia de Família da Universidade Católica do Salvador (UCSAL). 
observação participante constituiu-se na técnica de coleta de dados (Cerveny, 2000, p. 98).

Bowen foi um estudioso, investigador e professor considerado um teórico inovador da terapia de família. Seu arcabouço teórico concentra-se em torno de duas forças vitais que se contrabalançam: aquelas que levam a pessoa à união com sua família e aquelas que a impulsionam para se libertar rumo à individuação. Quando ocorre um desequilíbrio dessas forças em direção à união, ocorre fusão, aglutinação e indiferenciação. Essas noções estão imbricadas, no estudo da complexidade da formação emocional do indivíduo, em torno dos conceitos de massa indiferenciada do ego; diferenciação do self; processo de projeção familiar; processo de transmissão multigeracional; posição entre irmãos; e triângulo, que apresentaremos a seguir (Bowen, 1989; Kerr \& Bowen, 1989). São esses conceitos que exporemos a seguir, baseados no autor e em autores que o complementam.

Bowen e sua equipe, a partir de estudos sobre a esquizofrenia, em 1954, observaram um apego simbiótico do paciente à sua mãe, ampliando essa hipótese para os demais membros da família. Desse olhar para a família e para o seu processo emocional, Bowen construiu seus principais conceitos.

O conceito de massa indiferenciada remete ao de fusão ou aglutinação, termo utilizado por Minuchin (1982) para se referir a um estilo transacional caracterizado por um "sentimento de pertencimento que requer uma máxima renúncia de autonomia" (p.60). Essa força de aglutinação em permanente tensão, exposta aos fatores externos que também exercem influência nas relações familiares, existe em todas as famílias, em variados graus de intensidade. $O$ estresse originado de diferentes fatores psicossociais aumenta a força de união que age sobre a massa indiferenciada do ego, propiciando uma maior aglutinação de seus membros.

Foley (1990) refere-se a três maneiras utilizadas pelo casal para controlar a intensidade da fusão do ego com a massa do ego da família. A primeira se expressa pelo conflito conjugal. A segunda é marcada pelo aparecimento de uma disfunção em um dos cônjuges - assim, um deles cederá ao outro, tornando-se dependente. A terceira maneira usada pela díade conjugal, visando aliviar a situação estressante, é a transmissão da tensão para um ou mais dos filhos, que apresentará algum sintoma.

Toda criança nasce fusionada, indiferenciada em relação à sua família. Durante seu desenvolvimento, sua principal tarefa será diferenciar-se para alcançar autonomia e independência. Na família, as crianças experimentam tanto o pertencimento quanto a diferenciação. Pertencer significa participar, saber-se membro desta família, partilhar as suas crenças, valores, regras, mitos e segredos. Diferenciar refere-se à afirmação de sua singularidade, à sua individuação e ao seu direito de pensar e expressar-se independentemente dos valores defendidos por sua família. 
Segundo Nichols e Schwartz (1998), a diferenciação do self, pedra fundamental da teoria de Bowen, é ao mesmo tempo um conceito intrapsíquico e interpessoal."A diferenciação intrapsíquica é a capacidade de separar o sentimento do pensamento" (p.312). Kerr e Bowen (1988) denominaram reação à resposta impulsiva.

A escala de diferenciação do self ajuda a compreender o processo de amadurecimento do indivíduo, as respostas significativas, o funcionamento e as disfunções ocorridas nos processos relacionais. Essa escala, de uma importância teórica mais do que classificatória, é dividida em quatro quadrantes: no quadrante inferior, a diferenciação do eu é mínima. As pessoas que funcionam nessa categoria vivem em um mundo de sentimentos e são quase inteiramente dependentes das demais. São pessoas incapazes de distinguirem a emoção da razão. São extremamente reativas e apresentam dificuldades relacionais. No segundo quadrante (25-50), estão aquelas pessoas ainda pobremente diferenciadas, mas capazes de funcionarem de maneira limitada. São pessoas facilmente influenciadas, pois não têm opiniões próprias. No terceiro quadrante (situado entre 50 e 75), estão pessoas que têm opiniões bem diferenciadas, conseguem assumir a "posição eu" e apoiar-se menos no julgamento dos outros. No quarto quadrante (situado entre 75-100), estariam aquelas dotadas de uma plena maturidade, que funcionariam com alto grau de independência. São pessoas seguras de si, com opinião bem definida, embora não necessitem expressá-las de forma dogmática ou rígida. Assumem responsabilidade por seus atos, são tolerantes a opiniões divergentes e não entram em debates para provar que estão certas.

A família é considerada uma unidade emocional. Segundo Papero (1998),"seus membros acham-se ligados uns aos outros de tal maneira que o funcionamento de cada um automaticamente afeta o dos demais" (p.72). O sistema emocional responde de acordo com forças externas à família, incluindo a família ampliada, situações de trabalho e fatores sociais. "Para um indivíduo ou grupo em particular, as seqüências comportamentais e interacionais que refletem o sistema emocional possuem uma característica de repetição" (Papero, 1998, p. 74).

O sistema emocional humano é passível de ser influenciado pela ansiedade crônica, (Kerr \& Bowen, 1988), um estado ou condição crônica de existência, independente de qualquer situação ou estímulo, gerando o apego ansioso,"uma forma patológica de ligação orientada pela ansiedade e pela emocionalidade que subvertem a razão e o autocontrole" (Nichols \& Schwartz, 1998, p. 310).

Nichols e Schwartz (1998) ressaltam que o apego emocional é um dos aspectos fundamentais da diferenciação. A dinâmica básica subjacente ao apego emocional seria a alternância entre ansiedade de separação e de incorporação. "A fusão emocional entre a mãe e o filho(a) pode assumir a forma de um vínculo dependente afetivo ou uma luta conflituosa" (p. 314). 
Projeção familiar é o processo pelo qual os pais transmitem aos filhos sua imaturidade e sua indiferenciação conforme expressas no relacionamento (Kerr \& Bowen, 1988). A projeção é diferente do "cuidado" e se caracteriza por uma preocupação ansiosa, confusa e excessiva com um ou mais filhos ou filhas. O filho escolhido, objeto da projeção dos pais, torna-se o mais ligado a eles e, conseqüentemente, aquele com um nível mais baixo de diferenciação do self. Esse filho busca ativamente o papel de bode expiatório e "apesar disso, a 'vítima' recebe seu carinho, ainda que negativo" (Foley, 1990, p. 105).

A mãe transmite sua ansiedade ao transferir para o filho uma carga emocional de suas frustrações, ao invés de estimulá-lo no seu processo de diferenciação. Dessa forma, prejudica emocionalmente o filho, que se torna infantilizado, desenvolvendo aos poucos sintomas de imaturidade psicológica.

O processo de transmissão multigeracional, também exposto por Kerr e Bowen (1988), corresponde à passagem do processo emocional da família através de várias gerações, tanto do marido quanto da mulher. O fluxo de ansiedade de uma família pode ser tanto vertical quanto horizontal.

O fluxo vertical em um sistema inclui padrões de relacionamento e funcionamento que são transmitidos para as gerações seguintes de uma família principalmente através do mecanismo de triangulação emocional... questões opressivas familiares com os quais nós crescemos... O fluxo horizontal no relacionamento familiar inclui a ansiedade produzida pelo estresse na família conforme ela avança no tempo, lidando com as mudanças e transições do ciclo de vida familiar. (Carter \& Mc Goldrick, 1995, pp. 11-12)

Eventos estressantes podem levar a família à disfunção por várias gerações posteriores. Retratam uma situação de aumento das tensões familiares eventos tais como: morte prematura, nascimento de uma criança deficiente, enfermidade, acidente, entre outros. Segundo Papero (1998), aplica-se o conceito de processo de transmissão multigeracional "ao modo pelos quais os processos de projeção familiar, repetidos de geração em geração durante longos períodos de tempo, levam diferentes ramos de uma família a alcançar níveis mais baixos ou mais altos de diferenciação" (p. 87).

A escolha do parceiro no matrimônio está relacionada ao nível de diferenciação do eu. A pessoa tende a escolher o parceiro com nível de diferenciação semelhante ao seu. Os vários filhos podem ter níveis diversos de diferenciação, mas não muito distantes daqueles alcançados pelos pais.

É importante a posição da pessoa na família de origem e nas relações futuras com o cônjuge (Bowen, 1991). A posição fraterna pode predizer algumas dificuldades conjugais. Aqueles que contraem matrimônio com cônjuge da mesma posição fraterna terão mais dificuldades de adaptar-se ao casamento do que aqueles que se casam com cônjuge de posição com- 
plementar. A relação entre irmãos é considerada "o primeiro laboratório social, no qual as crianças podem experimentar relações com iguais. Dentro desse contexto, as crianças apóiam, isolam, escolhem um bode expiatório e aprendem umas com as outras" (Minuchin, 1982, p.63).

O conceito de triangulação se refere a um sistema inter-relacional entre três pessoas, envolvendo sempre uma díade e um terceiro, que será convocado a participar quando o nível de desconforto e de ansiedade aumentar entre as duas pessoas. Uma delas, então, buscará uma terceira para aliviar a tensão. Os triângulos aparecem no processo emocional interacional que se estabelece no sistema familiar e transgeracional. Calil (1987) considera o triângulo como "um bloqueador das emoções de um sistema" (p. 103).

Sair das triangulações orienta o outro a um relacionamento em nível superior de maturidade. Os triângulos, para Kerr e Bowen (1988), "são para sempre" (p. 135). Em situações de menor tensão, permanecem latentes, reaparecendo quando os conflitos recrudescem. Assim, os triângulos são susceptíveis à ansiedade, tornando-se mais ou menos ativos em situações de tensão. Nesse sentido, o processo de triangulação constitui um mecanismo de resposta que acontece nos processos relacionais ante situações estressantes.

Na família, observam-se vários triângulos que se formam e se desfazem de forma repetitiva. Os triângulos não são fixos nem estáticos, sofrendo deslocamentos, a depender do nível de ansiedade e da dinâmica interna da família. É importante ressaltar que estão ligados a uma unidade emocional mais ampla, de onde também recebem influência, denominada triângulos entrelaçados, onde "a ansiedade, incapaz de ser contida dentro de um triângulo, se expande para um ou outro triângulo" (Kerr \& Bowen, 1988, p. 139). Esses autores denominam esse processo de ativação de triângulos imbricados, que podem ser de difícil observação.

Para Andolfi e Ângelo (1988), compreender a entrada de um terceiro elemento nas díades em situação de conflito "acrescenta uma dimensão desconhecida à interação, viabilizando alianças, além de uma nova relação de inclusão-exclusão... como também pode estimular a manifestação de recursos individuais ocultos e a evolução do sistema" (p. 33).

O entendimento dos processos de triangulação está ligado à compreensão de como se dá o processo de comunicação, como a partir da linguagem não-verbal - tom de voz, mudanças na postura corporal e outros sinais não verbais - que podem ou não ativar os triângulos.

A teoria boweniana enfatiza que, para compreender a família, é necessário desvelar o que acontece nas gerações que a precederam e ampliar o olhar para a família extensa, elucidando vários nós que, no estudo estritamente da família nuclear, podem permanecer obscurecidos. Cada indivíduo: 
é parte de uma rede de relações que envolvem as respectivas famílias de origem.... Através de interações que permitem a cada pessoa experimentar o que é e o que não é admissível na relação, é criada a base de uma unidade sistêmica. (Andolfi,

Ângelo, Menghi, \& Corigliano, 1984, p. 18)

Não existem famílias isoladas, e sim uma complexidade social, econômica e política em que essas famílias estão imbricadas (Rabinovich, 2002). Pensar a diferenciação do self familiar atualmente requer entender as novas configurações da família em suas várias expressões do processo emocional societário. Note-se que o pólo de tensão nas famílias aumenta, complexifica-se e expande-se rapidamente, mediado pelos meios de comunicação e pelos avanços tecnológicos que ocorrem na sociedade contemporânea.

As famílias constituídas hoje passam por mudanças sucessivas, de modo que, "se reconhecermos que há novos e diversos tipos de famílias, também deveríamos, no mínimo reconhecer que o ciclo pelos quais elas passam também pode ser diferente" (Molina-Loza, 1998, p. 69). Na medida que há uma complexificação dos modos de vida devido a vários estresses, como o desemprego e a exclusão, Andolfi e Nichilo (1991, p. 11) consideram que a retomada das gerações anteriores, conforme proposto por Bowen, encontra uma variável não prevista por ele - o tempo - quando os valores das gerações anteriores não são mais compreendidos pelas gerações atuais.

Assim, compreender o limite da teoria de diferenciação do self passa pela compreensão da forma como as famílias estão estruturadas nos dias atuais.

Exporemos, a seguir, o estudo de caso a partir do qual os conceitos acima expostos serão apresentados e elaborados.

\section{O estudo de caso}

O casal foi atendido no Centro de Orientação da Família durante um ano.Sérgio, 33 anos, e Ana Maria, 27 anos; ambos com o segundo grau completo. Têm uma pequena casa comercial, onde trabalham juntos. Têm dois filhos, Clara, de 12 anos, e Matheus, de 4 anos. Estão casados há 12 anos, quando Ana Maria ficou grávida aos 15 anos, tendo Sérgio 19 anos.

O casal chegou ao Centro de Orientação por meio de um religioso, com queixa de desgaste na relação, gerado pelo ciúme, desconfiança, acomodação e rivalidade. Sérgio buscou ajuda junto à igreja e ao grupo de casais da paróquia para melhorar seu relacionamento com Ana Maria. Ana Maria estava fazendo um tratamento para emagrecer e parecia descontrolada, negligenciando o cuidado com as crianças, gastando desnecessariamente, além de ter abraçado e beijado um rapaz do bairro, dando a entender que estava interessada nele. 
Sérgio se sente ameaçado pela infidelidade de Ana Maria. Está constrangido com a situação, arrasado.Tem medo de que a esposa Ihe seja infiel, não sabe mais o que fazer. Não gostaria de ver sua família desmoronada.

Conheceram-se em Serrinha, no interior da Bahia, cidade onde Sérgio residia e Ana Maria costumava passar as férias. Apaixonaram-se imediatamente e buscavam sempre um pretexto para se encontrarem. Sérgio já trabalhava no interior e era considerado um rapaz muito responsável para a sua idade.

Ana Maria engravidou e, como estavam apaixonados, não viram nenhum problema. O pai dela arranjou um emprego para Sérgio num estabelecimento comercial de sua propriedade, no qual trabalhou durante 7 anos como gerente.

A propriedade comercial do sogro estava dando prejuízo quando Sérgio assumiu a gerência; porém, com ele à frente, o negócio prosperou. Sérgio sente-se incomodado com o jeito como funciona a família de Ana Maria - sem se importar com nada.

Sérgio nasceu em 1972, sendo o quinto entre seis filhos: quatro muIheres e dois homens. Vivia na roça, com os pais e os irmãos. Seus pais trabalhavam muito para darem aos filhos "o que eles não tiveram". Tratava-se de uma família emaranhada, na qual todos participavam de tudo e interferiam nos problemas uns dos outros. Era uma vida dura, como diz Sérgio:

Tempo difícil. Pouca comida, poucas roupas. Brinquedos, só tinham os que fabricavam. Não havia estrada para carro, nem energia elétrica, nem sabia o que era. Os pais falavam muito do tempo da ditadura militar, onde pouco se vendia e muito pouco se podia comprar.

Ele se lembra de ter visto, quando era pequeno, seu pai brigando com as duas irmãs mais velhas. Toda manhã, às cinco horas, o pai de Sérgio obrigava-as a irem sozinhas à escola. Sérgio via a mãe chorando, quando as irmãs chegavam depois de andarem tanto e "o pai ainda as obrigava a fazerem o serviço de casa".

Sérgio conta que o pai ia para a feira vender mercadorias e comprar alimentos e demorava muito. Sérgio ia com a mãe e a irmã caçula para a estrada e rezavam para o pai chegar. Quando ele chegava, sentiam uma alegria enorme, embora muitas vezes o pai chegasse embriagado. Brigava e vomitava. Muitas vezes, o pai não chegava.

Aos 17 anos já namorava, mas não gostara de ninguém até conhecer Ana Maria. Uma forte ligação se estabeleceu entre os dois. No entanto, Ana Maria engravidou, o que soube por ter ido visitá-la ao acaso.

"Minha cabeça parecia que ia explodir. Ana Maria queria casar-se logo, mas eu pedi alguns meses até que casamos".

Ana Maria nasceu em 1978, primeira filha entre quatro irmãos. Posteriormente, a mãe teve mais seis filhos, sendo que três de uma segunda 
união, dois de uma terceira e, finalmente, mais um de uma quarta união. $A$ mãe nunca foi casada.

Ana Maria relata a sua história começando pela gravidez da mãe, que tinha mais ou menos a mesma idade que Ana Maria quando engravidou. Relata que a gravidez da mãe foi tumultuada por ter engravidado de um homem casado, rejeitada pela família do pai e perseguida pela esposa do mesmo, o que as obrigava a uma contínua mudança de moradia.

Morei em muitas casas... mas odiava aquilo, acho que hoje sou tão chata em relação às minhas coisas por isso, pois minha mãe permitia que os vizinhos entrassem, pegassem o que quisesse. Mas apesar de toda dificuldade, nesta época eu fui feliz, pois para mim não era importante o lugar que eu morava e sim com quem morava.

Porém, a mãe decidiu enviá-la para morar com as tias, o que constituiu um "pesadelo. Tudo era muito certo, nada era fora do lugar, toda a vida e a alegria que existia dentro de mim era sufocada ali".

Ao se referir a Serrinha, Ana Maria mostra alegria e prazer, lembrando-se das boas recordações das férias que lá passavam. Foi sempre especialmente ligada ao pai. Esforçava-se em tudo para que o pai se orgulhasse dela. Seu vínculo ficou abalado com o nascimento de um irmão, que a tirou do lugar central ocupado.

A partir desta mulhere deste filho, vieram muitos outros e eu acabeime acostumando e me afastei muito do meu pai, mas só emocionalmente, pois, fisicamente, estava sempre com ele. Como eu tinha medo de perdê-lo, eu ia sempre com ele e suas "namoradas".

Aos 13 anos, começa a namorar escondido, por temer a reação do pai. Ao ser pega, o pai bate e passa a vigiá-la. É quando conhece Sérgio.

"Eu achava que ainda era apaixonada por Carlos, mas com o tempo ele me conquistou. Queria ter uma família com ele. Uma família de verdade, bem diferente da minha".

Porém, após algum tempo, o casamento entra em crise por ela perceber o marido como uma cópia do pai.

Não queria mais aquele casamento, não queria mais aquela vida e quis me separar. Mas Deus coloca sempre amigos em nossas vidas, quando perdemos as forças e a razão. E hoje esses amigos me ajudam a ver onde eu errei e a consertar o que partiu. E a reencontrar a beleza e o amor da minha vida de adolescente.

A narrativa de Sérgio e Ana Maria remete aos níveis de diferenciação, inicialmente, com as famílias de origem (quadro). 


\section{Quadro}

Bloqueios e facilitadores da diferenciação do self

\begin{tabular}{|c|c|}
\hline BLOQUEIOS À DIFERENCIAÇÃO DO SELF & FACILITADORES DA DIFERENCIAÇÃO DO SELF \\
\hline $\begin{array}{l}\text {. Suspeita de infidelidade; } \\
\text {. Desorganização na família de origem } \\
\text { - forte fusão do ego famíliar; }\end{array}$ & $\begin{array}{l}\text {. Aprender a complementaridade; } \\
\text {. Psicoterapia; }\end{array}$ \\
\hline $\begin{array}{l}\text { Gravidez na adolescência; } \\
\text {. Baixo nível de diferenciação com a } \\
\text { família de origem; }\end{array}$ & $\begin{array}{l}\text {. Desejo de manter a família reunida; } \\
\text {. Constituição de rede de apoio e } \\
\text { solidariedade; }\end{array}$ \\
\hline $\begin{array}{l}\text { Dificuldade de diferenciar o } \\
\text { pensamento do sentimento; }\end{array}$ & . Retorno às famílias de origem; \\
\hline . Projeção familiar - sujeitos a fusões; & $\begin{array}{l}\text { A presença dos filhos como } \\
\text { diferencial para mover o casal na } \\
\text { busca de si mesmo; }\end{array}$ \\
\hline $\begin{array}{l}\text {. Lugar dos irmãos (filho mais velho x } \\
\text { filho do meio); }\end{array}$ & - Amizade e diálogo entre o casal; \\
\hline $\begin{array}{l}\text {. Dinâmica parental x dinâmica do } \\
\text { casal; }\end{array}$ & $\begin{array}{l}\text {. Fortalecimento de crenças: fé, } \\
\text { esperança, amizade, sonhos; }\end{array}$ \\
\hline $\begin{array}{l}\text {. Ciclo rival: filhos pequenos e filhos na } \\
\text { escola com frágil estrutura do casal; }\end{array}$ & $\begin{array}{l}\text {. Construção de projetos em comum: } \\
\text { no trabalho, na comunidade e na } \\
\text { família; }\end{array}$ \\
\hline $\begin{array}{l}\text { - Repetição de padrões familiares } \\
\text { (trabalho excessivo x entrega ao prazer } \\
\text { sem limites); }\end{array}$ & $\begin{array}{l}\text { Busca de outros recursos para o } \\
\text { crescimento do casal além da terapia: } \\
\text { cursos; oficinas; pastoral da família; }\end{array}$ \\
\hline $\begin{array}{l}\text {. Transmissão de imaturidade } \\
\text { transgeracional; }\end{array}$ & . Fronteiras flexíveis. \\
\hline . Família emarenhada. & \\
\hline
\end{tabular}

Ana Maria aparece em simbiose com o pai:era seu pai quem pensava, escolhia e propunha. A mãe, por sua vez, apresentava baixo nível de diferenciação, sem crenças nem convicções próprias.

A infância de Ana Maria divide-se entre uma mãe permissiva e tias rígidas, em que o prazer é negado, lançada entre opostos de tudo ou nada poder. O pai, permissivo como a mãe,é, porém, capaz de satisfazer seus desejos. As dificuldades com o pai surgem na fase de pré-adolescência, quando, apaixonada por ele, tendo-o só para si, Ana Maria vê-se na iminência de dividi-lo com um novo irmão, primeiro filho de uma outra união do pai. 
Ana Maria depende de seus pais. "Nunca fiz nada que ele se envergonhasse". Tenta corresponder às expectativas parentais: boazinha, boas notas. Mantendo-se triangulada com o pai, não consegue abrir um lugar para o irmão. Incapaz de separar suas emoções, divorcia-se emocionalmente do pai no momento em que começa a se distanciar dele e a elaborar o seu mundo particular, definido por ela como seu território, já não se percebendo como a filha preferida. O nascimento de irmão leva Ana Maria ao rompimento emocional, que Bowen denomina "divórcio emocional":

"Me afastei muito de meu pai, mas só emocionalmente, pois fisicamente estava sempre com ele".

Ana Maria muda-se de sua casa, mas transfere para Sérgio e para a relação conjugal as questões não resolvidas com o pai e com a mãe. Ana Maria passa a se relacionar com Sérgio da mesma forma que se relacionava com o pai. Ana Maria experimenta com Sérgio o padrão de conduta relacionado ao pai. Transgride, compra compulsivamente e Sérgio reclama, pois não gosta da forma como Ana Maria se veste. Na ausência de Sérgio, Ana Maria repete o que fazia com o pai: se diverte.

as questões que os parceiros não resolveram com as suas famílias de origem influenciarão, provavelmente, a escolha conjugal, e poderão interferir no equilíbrio do novo casal. Há, na verdade, inúmeras variantes meio ocultas, encerradas na história de vida de cada um, que acabam tornando-se visíveis e assumem uma nova feição, no cerne da família nuclear, que se vai formando. (Silva, 2003, p. 235)

Dessa forma, o amor de Ana Maria por Sérgio foi uma repetição de sua relação com o pai, enquanto ela era a preferida de Sérgio. Com o nascimento da primeira filha, Clara, Ana Maria começa a perceber o amor de Sérgio pela filha, depois completado com o nascimento do segundo filho, Matheus. Ana Maria já não tinha o marido só para si.

O casal vive dois momentos diferenciados do ciclo vital, um filho pequeno e outro adolescente.

Nas famílias gerando filhos a questão da individuação aparece novamente quando o casal, por exemplo, não sabe administrar a responsabilidade parental com a dinâmica da relação marido e mulher; quando não sabem fazer a passagem da díade marido e mulher para o triângulo pai x mãe x filho; quando a mãe e o filho formam uma unidade simbiótica tão forte que a mãe não consegue introduzir o pai na relação; quando existe o medo de que as falhas como pais provoquem danos permanentes nos filhos. (Teixeira, 1996, p. 114)

Sérgio e Ana Maria não conseguem fazer essa passagem."Saber fazer essa passagem ocasiona perdas dolorosas mas também contribui para o crescimento na jornada de individuar e pertencer" (Teixeira, 1996, p. 115). 
Sérgio repete o padrão de sua família de origem: dedica-se exaustivamente ao trabalho, para cuidar da família. Ama os filhos e coloca esse sentimento acima de tudo. Sérgio expressa o seu desejo de unir a família, de estar com os filhos a qualquer preço, colocando o dever acima de tudo.

Ana Maria tem de dividir o amor do marido com Clara e Matheus. Um novo divórcio emocional acontece. Como forma de ferir Sérgio, Ana Maria usa o mesmo padrão de sua família de origem, especificamente de seu pai: primeiro, com a permissividade, identifica-se com a sua mãe e começa a negligenciar, sair sem dar nenhuma satisfação, flertar, conversar com rapazes até chegar a dar um beijo num jovem, ferindo profundamente Sérgio. Nesse momento, o segundo divórcio emocional acontece nessa família. Sérgio se desespera. Busca ajuda religiosa, triangulando-se; em seguida, pede a ajuda terapêutica.

A ligação de Ana Maria com Sérgio assemelha-se à ligação emocional triangulada que cada um teve no passado, com a sua família de origem. $\mathrm{Na}$ história dessa família, verifica-se uma sucessão de triângulos, começando com a mãe de Ana Maria, que triangula com os vizinhos, buscando fortalecimento e possíveis pseudo-egos. Ana Maria triangula com o pai, mas este se afasta; então ela triangula com os amigos. No entanto, tendo que estar sempre mudando de residência, busca apoio emocional nos diferentes grupos sociais em que transita, através de amigos e namorados."Aqueles que manejam a ansiedade através do distanciamento e do retraimento farão o mesmo em seus casamentos" (Nichols \& Schwartz, 1998, p. 317). Assim, pode-se dizer que a união desse casal, na sua tarefa inicial de dois indivíduos como troca de dois sistemas inteiros e uma justaposição para desenvolver um terceiro, simbolicamente não aconteceu.

De uma família emaranhada no passado a uma família emaranhada no presente, Ana Maria relata que o filho Matheus vai sempre para o seu quarto dormir, parecendo repetir a sua ligação com o pai, no passado.

Encontrar Sérgio, a gravidez e o casamento proporcionaram a Ana Maria o apoio que procurava: encontrar alguém que cuidasse dela e lhe tirasse da solidão deixada pelo pai, que, dividindo seu amor com tantas mulheres, já não tinha tempo para se dedicar a ela com exclusividade.

Sérgio, subjugado pelas exigências do pai, exposto ao trabalho cedo, tendo que enfrentar a dureza da vida, encontra em Ana Maria a resposta para todas as suas inquietações e decide depositar tudo nesse casamento. A partir de então, cuidar da mulher grávida, trabalhar para sustentá-la, cuidar da filha Clara e depois de Matheus são suas metas primordiais. Seus sonhos de continuar os estudos, passear, curtir a vida são adiados. Sérgio se atira com toda garra ao trabalho, levando consigo Ana Maria, que, durante um tempo, aceita a direção de Sérgio, sem questioná-lo ou contestá-lo.

Ana Maria, porém, não deseja só isso. Tem sonhos e, como na infância tinha seu pai para satisfazer seus desejos, esbarra em Sérgio, que repete o papel do pai, de trabalhar, trabalhar, trabalhar. 
O conflito do casal se acirra, aumentando a ansiedade, quando Ana Maria não quer abrir mão do desejo e deixa tudo em busca de satisfazê-lo. Esse, porém, se apresenta difuso na sua fala: "reencontrar o amor de minha adolescência". O desejo infantil de total fusão com o pai é transferido para Sérgio, mas Ana Maria não deseja Sérgio, deseja o pai.

Ana Maria experimentou a "liberdade" (ou ficou à deriva), na mais tenra idade, embora mediada por limites que vinham na forma de dupla linguagem, na voz do pai - "você pode"/"você não pode" -, fusão, simbiose, apego possessivo, barreiras a impedir o seu crescimento emocional. Daí, ela desejar encontrar sua liberdade.

Ana Maria continua fusionada ao pai, sendo iminente o retorno a essa triangulação. A diferenciação não é expressa apenas na qualidade dos indivíduos, mas na dos seus relacionamentos. Tanto Ana Maria quanto Sérgio estão expostos a relacionamentos carregados de indiferenciação, com ansiedade crônica alta em seu sistema familiar nuclear. Por isso, não conseguem lidar com essa ansiedade, ou mesmo neutralizá-la. Os padrões de comportamento vivenciados na família de origem se atualizam na vida conjugal.

Ana Maria, vulnerabilizada pela ausência de diferenciação na sua família de origem, apresenta-se mais propensa a desenvolver sintomas, tornando-se o centro do conflito do relacionamento conjugal. Sua capacidade emocional a impede de lidar com o estresse.

A gravidez de Ana Maria interrompe o processo do casal se libertar da massa indiferenciada do ego familiar. Sem conseguir lidar com suas emoções, busca alívio: cinema, comidas, revistas, roupas extravagantes, flertes e realização de desejos que se multiplicam.

No momento atual, Ana Maria começa a ver na filha Clara, que se torna mocinha e é muito apegada a Sérgio, uma rival que vem lhe roubar o amor substituto. Brigam, desentendem-se. O sistema conjugal se fechou e cada um projeta no outro a sua frustração.

Clara, que está se aproximando em idade do mesmo momento em que a mãe estava quando engravidou, enfrenta Ana Maria no desejo de mais liberdade, buscando a companhia de colegas. Sérgio diz que Ana Maria não a está acompanhando, enquanto esta afirma que conversa com a filha. Clara triangula-se com o pai. Este busca torná-la sua confidente, quando é orientado pelo processo terapêutico.

Encontram-se, nessa posição de adolescência, três gerações: a mãe de Ana Maria, que engravidou no passado; Ana Maria, que fez o mesmo; e agora Clara, com 12 anos, aproximando-se do mesmo momento, embora Sérgio afirme a maturidade de Clara. Na sua inquietação, ele traz a preocupação de que se repita com Clara algo semelhante à mãe e à avó, por isso quer protegê-la. 
Os pais de Sérgio mantiveram os filhos muito próximos a eles, durante a infância e a adolescência, fusionados ao ego familiar, acostumando Sérgio ao trabalho desde a mais tenra idade. Já a independência afetiva não veio da mesma forma, precoce, e faz com que Sérgio leve para sua família nuclear limitações, decorrentes das repressões do pai, que o levaram a se tornar obediente e submisso.

As questões não resolvidas, que foram passadas da geração anterior, potencializaram-se ao se cruzarem com o estresse atual do casal, surgido em diferentes momentos do ciclo de sua vida - na formação do casal, na chegada do primeiro filho, no início da vida escolar dos filhos e na adolescência de Clara - aumentando a ansiedade.

Sérgio e Ana Maria chegam à instituição em busca de ajuda, mas trazem crenças, esperança e o desejo comum de fazerem o melhor para seus filhos, mas não sabem o que fazer. Corroborando essa idéia, Walsh (2003) enuncia:

Pessoas altamente resilientes buscam ajuda quando necessário, recorrendo a sistemas de apoio familiares, sociais e religiosos, assim como a profissionais de ajuda. $\mathrm{O}$ apoio mútuo promove a resiliência dos relacionamentos, fortalecendo as famílias e suas comunidades. (p.75)

No processo terapêutico, aos poucos, o casal vai se conscientizando desses padrões e o quanto os mesmos precisam ser modificados. Algumas forças, internas e externas, auxiliam o casal na busca de mais diferenciação. Percebe-se que a comunicação entre seus membros flui de forma clara; sentem-se à vontade para falarem de suas dificuldades. Nesse sentido, aproximam-se de Carneiro (1983), para quem "os membros da família podem expressar uns aos outros a sua agressividade, ao mesmo tempo em que há muitos espaços para que a afeição física e o carinho sejam trocados entre eles. A individuação de cada membro está presente sem comprometer a integração do grupo familiar" (p. 125).

À medida que a família se torna mais diferenciada, busca ampliar sua rede de apoio, inclusive exercendo o papel de estimuladora dessa rede de relação ampliada. $O$ casal busca viver a vida familiar com responsabilidade, incrementando relacionamentos com outras pessoas que acreditam neles, com quem podem se identificar e reunir forças para superar a crise e as dificuldades (Walsh, 2003).

Sérgio e Ana Maria confirmam a aplicabilidade dos conceitos bowenianos, quando começam a diferenciar as questões familiares de suas experiências vividas nas respectivas famílias de origem, ressignificando-as na sua vida atual, buscando um caminho próprio, único, onde há lugar para escolhas pessoais e do casal. Cada um, dentro do processo terapêutico, teve oportunidade de rever as suas escolhas. Pois "não basta pensar que você escolheu; você deve recordar-se também que o outro se tornou um 
bem que lhe é dado, o seu próprio bem" (Dor, 2003, p.49). Como afirma Marie Dor (2003):"A amizade poderá crescer se ambos aprenderem a valorizar as qualidades do outro, a lhe dar espontaneamente autoridade nos setores em que ele é mais capaz" (p. 53).

Clara e Matheus representam um bem para Sérgio e Ana Maria, e esse foi o diferencial a mover o casal na busca de si mesmo. Era vital para cada um se encontrar para não perder seu "bem comum", ou seja, seus fiIhos. Nenhum dos dois, no momento da crise, abriu mão disso. Ficar juntos, rever suas questões como casal, foi o caminho que Sérgio e Ana Maria encontraram para preservarem os filhos. Dessa forma, o casal pôde também encontrar a si mesmo como casal e se diferenciar, primeiro de suas famílias de origem, depois, um do outro, tornando-se mais preparados para ser responsivos aos filhos.

O sofrimento de Ana Maria e Sérgio, a coragem e a determinação de encarar a "si mesmos", ao mesmo tempo disponibilizou a opção de olhar outros casais que formam a sua rede de solidariedade. $O$ casal fortalece a sua rede de pertença e essa, por sua vez, os reconhece e os diferencia.

\section{Considerações finais}

Ana Maria e Sérgio, pouco diferenciados em suas famílias de origem, ao se unirem no casamento, com níveis de diferenciações semelhantes, aumentaram o nível da ansiedade e, assim, a capacidade de lidar com ela. Buscaram triangular-se de diferentes formas, tendo sido necessário desfazer triângulos que continuavam ativos trazendo carga emocional excessiva para o relacionamento atual. Enquanto estiveram emocionalmente triangulados no passado, permaneceram paralisados nas posições que ocuparam em suas famílias de origem, e o processo de crescimento pessoal estacionou. Sujeitos a fusões emocionais, transmitidas transgeracionalmente, a emoção de Ana Maria e Sérgio inundou sua capacidade elaborativa, prejudicando o funcionamento e a competência racional de cada um.

O estudo realizado aponta que as histórias dessa família se fundiram para gerar uma nova história, já não havendo mais apenas a família multigeracional, mas também famílias inter e intra-geracionais. A experiência dessa família mostrou ser, também, possível a construção de redes de apoio, constituídas pela igreja, escola e universidade. 


\section{Family and the differentiation process in Murray Bowen theory: a case study}

Abstract: This study aimed to investigate the applicability of Murray Bowen's theory of self differentiation to family therapy. It focused one family showing how the couple's life histories, starting from the very first triangulations in the nuclear and extended families were transmitted between generations until generate a renewed history for the couple and their own family.

Keywords: Family. Differentiation of the self. Emotional system. Multigenerational.

\section{Famille et le processus de différentiation du poin de vue de Murray de Bowen: um étude de cas}

Résumé: Cet étude a pour but présenter l'application du concept de différentiation du self selonMurray Bowen à la therapie de la famille. Il a focalisé une famille en montrant comment l'histoire de vie de la pareille, en commençant par les premières triangulations, dans la famille nucleaire et dans la famille étendue, ont été transmises entre générations pour finir en formant une histoire renouvelée du couple et de sa propre famille.

Mots-clés: Famille. Differentiation du self. Sistème emotional. Multigénérational.

\section{Familia y el proceso de diferenciación desde el punto de vista de Murray Bowen: un estudio de caso}

Resumen: El estudio tuvo como objetivo investigar la aplicabilidad del concepto de diferenciación del self elaborado por Murray Bowen en la terapia de la familia. Enfoca la historia de una familia que muestra cómo las historias de la vida de la pareja, desde los primeros triangulaciones tanto en la familia nuclear como en la larga, fue transmitida entre generaciones mediante la creación de una historia renovada de la pareja y sus familias.

Palabras-clave:Familia. La diferenciación del self.Sistema emocional de las relaciones. Multigeracional. 


\section{Referências}

Andolfi, M., \& Ângelo, C. (1988). Tempo e mito em psicoterapia familiar (F. Desidério, trad.). Porto Alegre: Artes Médicas.

Andolfi, M., Ângelo, C., Menghi, P., \& Corigliano, A. M. N. (1984). Por trás da máscara familiar: um enfoque em terapia de família (M. C. R. Goulart, trad.). Porto Alegre: Artes Médicas.

Andolfi, M., \& Nichilo, M. D. (1991). Introducción. In M. Bowen, De la familia al individuo: La diferenciación del sí mismo en el sistema familiar (pp. 9-18). Buenos Aires: Paidós.

Bowen, M. (1989). La terapia familiar en la práctica clínica. Fundamentos teóricos (Vol. 2: Aplicaciones). Bilbao, Spain: Desclee de Brouwer.

Bowen, M. (1991). De la familia al individuo: la diferenciación del sí mismo en el sistema familiar. Buenos Aires: Paidós.

Calil, V. L. L. (1987). Terapia familiar e de casal: introdução às abordagens sistêmica e psicanalítica. São Paulo: Summus.

Carneiro, T. F. (1983). Família diagnóstico e terapia. Rio de Janeiro: Zahar.

Carter, B., \& Mc Goldrick, M. (1995). As mudanças no ciclo de vida familiar: uma estrutura para a terapia familiar. In B. Carter \& M. Mc Goldrick, As mudanças no ciclo de vida familiar: uma estrutura para a terapia familiar (M. A. V. Veronese, trad., 2a ed., pp. 7-29). Porto Alegre: Artes Médicas.

Cerveny, C. M. O. (2000). A família como modelo - desconstruindo a patologia. São Paulo: Livro Pleno.

Dor, M. E. (2003). Relações interpessoais na família: contribuição para uma análise filosófica das relações familiares. In J. C. Petrini, L. V. C. Moreira \& M. A. R. Alcântara (Orgs.), Família XXI: entre pós-modernidade e cristianismo (pp. 45-58). São Paulo: Companhia das Letras.

Foley, V. D. (1990). Introdução à terapia familiar (J. O. A. Abreu, trad.). Porto Alegre: Artes Médicas.

Kerr, M. E., \& Bowen, M. (1988). Family evolution: An approach based on Bowen theory. New York: W. W. Norton \& Company.

Mc Goldrick, M. (1995). Etnicidade e o ciclo de vida familiar. In B. Carter \& M. Mc Goldrick, As mudanças no ciclo de vida familiar: uma estrutura para a terapia familiar (M. A. V. Veronese, trad., 2a ed., pp. 65-83). Porto Alegre: Artes Médicas.

Minuchin, S. (1982). Famílias: funcionamento \& tratamento (J. A. Cunha, trad.). Porto Alegre: Artes Médicas.

Molina-Loza, C. A. (1998). Chaves para uma terapêutica da família: conhecer e compreender família brasileira. Belo Horizonte: Arte Sã.

Nichols, M. P., \& Schwartz, R. C. (1998). Terapia familiar: conceitos e métodos (M. F. Lopes, trad., 3a ed.). Porto Alegre: Artes Médicas. 
Papero, D. V. (1998). A teoria sobre os sistemas familiares de Bowen. In M Elkaim (Org.), Panorama das terapias familiares (E. C. Mellen, trad., Vol. 1, pp. 71-100). São Paulo: Summus.

Rabinovich, E. P. (2002). Contextos coletivistas de desenvolvimento: uma análise comparativa intercultural. In E. R. Lordelo, A. M. A. Carvalho \& S. H. Koller (Orgs.), Infância brasileira e contextos de desenvolvimento (pp. 165-204). São Paulo: Casa do Psicólogo.

Silva, C. N. (2003). Casamento: união de duas famílias e formação de um novo casal. In J. C. Petrini, L. V. C. Moreira \& M. A. R. Alcântara (Orgs.), Família XXI: entre pósmodernidade e cristianismo (pp. 221-244). São Paulo: Companhia das Letras.

Teixiera, M. Â. (1996). O processo de individuação no contexto familiar. Salvador: BDA Bahia.

Walsh, F. (2003). Crenças, espiritualidade e transcendência - chaves para a resiliência da família. In M Mc Goldrick, Novas abordagens da terapia familiar: raça, cultura e gênero na pratica clinica (M. Lopes, trad., R. R. Nahas, revisão científica, pp. 72-89). São Paulo: Roca.

Elizabeth Medeiros de Almeida Martins, Assistente Social, Docente da Universidade Católica do Salvador (UCSAL).Endereço eletrônico: elizabeth.martins@hotmail.com

Elaine Pedreira Rabinovich, Docente da Universidade Católica do Salvador (UCSAL). Endereço para correspondência: Rua Maranhão, 101. CEP 01240-001 - São Paulo-SP. Endereço eletrônico: elainepr@clas.com.br

Célia Nunes Silva, Médica, especilaista em terapia familiar. Docente da Universidade Federal da Bahia e da Universidade Católica do Salvador. Endereço eletrônico: celianunessilva@yahoo.com.br

Recebido em: 4/05/2007

Aceito em: 29/05/2008 